\title{
Inversion of chlorophyll-a concentration in Donghu Lake based on machine learning algorithm
}

\author{
Xiaodong Tang ${ }^{1}$ and Mutao Huang ${ }^{1}$ \\ ${ }^{1}$ Huazhong University of Science and Technology
}

January 25, 2021

\begin{abstract}
Machine learning algorithm, as an important method for numerical modeling, has been widely used for chlorophyll-a concentration inversion modeling. This work aims to build an effective inversion model of chlorophyll-a concentration in Lake Donghu based on machine learning algorithm. Toward this aim, a variety of models were built by applying five kinds of dataset and adopting back propagation neural network (BPNN), extreme learning machine (ELM), support vector machine (SVM). The model accuracy analysis results revealed that multi-factor dataset for modeling has the possibility to improve the accuracy of the single-factor model, and seven band combinations are better than seven single bands when modeling, Besides, SVM is more suitable than BPNN and ELM for chlorophyll-a concentration inversion modeling of Donghu Lake. SVM3 is the best inversion one among all multi-factor models that the MRE, MAE, RMSE of SF-SVM are 30.82\%, 9.44 $\mu \mathrm{g} / \mathrm{L}$ and $12.66 \mu \mathrm{g} / \mathrm{L}$, respectively. SF-SVM performs a better inversion effect than SF-BPNN and SF-ELM, the MRE, MAE, RMSE of SF-SVM are $28.63 \%, 13.69 \mu \mathrm{g} / \mathrm{L}$ and $16.49 \mu \mathrm{g} / \mathrm{L}$, respectively. In addition, the simulation effect of SVM3 is better than that of SF-SVM. On the whole, an effective model for retrieving chlorophyll-a concentration has been built based on machine learning algorithm, and our work provides a reliable basis and promotion for exploring accurate and applicable chlorophyll-a inversion model.
\end{abstract}

\section{Hosted file}

Manuscript.pdf available at https://authorea.com/users/391552/articles/505621-inversion-ofchlorophyll-a-concentration-in-donghu-lake-based-on-machine-learning-algorithm

\section{Hosted file}

Tables.pdf available at https://authorea.com/users/391552/articles/505621-inversion-ofchlorophyll-a-concentration-in-donghu-lake-based-on-machine-learning-algorithm

\section{Hosted file}

Figures.pdf available at https://authorea.com/users/391552/articles/505621-inversion-ofchlorophyll-a-concentration-in-donghu-lake-based-on-machine-learning-algorithm 